\title{
SUSTAINABLE CITIES: AN ANALYSIS OF THE CONTRIBUTION MADE BY RENEWABLE ENERGY UNDER THE UMBRELLA OF URBAN METABOLISM
}

\author{
A. BARRAGÁN ${ }^{1} \& \mathrm{~J}$. TERRADOS ${ }^{2}$ \\ ${ }^{1}$ Universidad Politécnica Salesiana, Carrera de Ingeniería Eléctrica, Ecuador. \\ ${ }^{2}$ Universidad de Jaén, Departamento de Ingeniería Gráfica, Diseño y Proyectos, \\ Escuela Politécnica Superior, España.
}

\begin{abstract}
The advantages and limitations of renewable energy have been discussed in various studies with an aim to increase its participation within the national energy mix. Options are being sought to encourage its use, mainly with the deployment of large-scale installations, which in many cases are farther from the centers of consumption. Such approach does not reduce neither the losses associated with transportation nor the lack of empathy of urban society with the externalities produced in areas placed far from the cities. As an alternative, it proposes to raise energy self-supply by promoting the use of endogenous resources that a city may possess. It was determined that there are several technologies that are available and that can be applied in a city. In spite of the fact that its implementation can be conditioned by the existence of the resource, costs or acceptance of the community, it is urgent that urban planners include the use sustainable energy, in order to meet future shortages of resource and adverse environmental phenomenon. With this proposal we conclude that using the approach of urban metabolism it is possible to promote the use of available renewable energy resources at cities. Based on a general approach, it is shown that it is possible to contribute to change a metabolic linear model to a metabolic circular model.
\end{abstract}

Keywords: planning cities, renewable energy, review, urban metabolism, urban sustainability.

\section{INTRODUCTION}

Cities are the result of energy development; which more than just grouping the bulk of humanity concentrate buildings, transportation systems, industrial processes and other innovations. Residents of cities import a large quantity of materials that are transformed through processes, which can cause critical impact at the regional and global levels [1]. More than $50 \%$ of the world's population lives in areas regarded as urban, which consume more than two-thirds of primary energy, which cause between $70 \%$ to $80 \%$ of greenhouse gas emissions associated with the use of energy, [2-4].

The expected environmental deterioration, including the future effects of global warming, requires that the manner in which cities are conceived is modified. As an essential step, the need for public policy and organized planning arises in order to cause a change in the behaviour of the population [5]. Given the enormous pressure exerted by the towns on the environment, the proposed changes are in fact an opportunity to promote sustainability $[6,7]$.

Alternatives have been proposed in several previous studies, and although they are not practical short-term solutions these must be analyzed further in cities where planning does not yet consider the decreasing consumption of material resources or energy [8,9]. 
Agudelo et al. [10], argues that planning should consider an efficient management of energy and materials for the development of urban infrastructure that reduces the constant requirement of these inputs. The long-term challenge is to reform energy policies so that they may allow a modification on the demand of the community [9], in turn, causing a change in consumer behaviour, the dynamics of the market and political forces.

As an alternative to change, autonomous provisioning arises; the same which is defined as the ability of a community to provide internally for their basic needs. In the case of energy, it is envisioned that the community consider their local geography, as well as the availability of its resources to meet their demands [9]. Therefore, every community must analyze their own needs and the resources that are available for those needs. From here, it requires studying the local characteristics to define individualizing the obstacles and opportunities [11], compared to the inevitable reduction of non-renewable energy resources.

The concept that allows to analyse this provision of the energy resource is urban metabolism (UM). This is understood as "the total sum of technical and socioeconomic processes that occur within cities that lead to the growth, production of energy and waste disposal" [12]. This approach of analysis has traditionally served to establish the material and energy flows of a city; and despite of it being referred to as a requirement and the establishment of a metabolic circular process, studies have focused marginally in energy sufficiency through renewable energies. Current technology allows for the provision of energy through renewable sources without requiring it to come from only large infrastructure. Vandevyvere and Stremke [13] state that efforts should be extended to include sustainable energy management in urban planning. A city with low energy imports and high presence of renewable energies, as well as an efficient use of energy, for example, will have an impact on the reduction of $\mathrm{CO}_{2}$.

This work identified, through a detailed literature review, the renewable technologies that can be applicable to the city. In addition, it justifies how renewable energies can be seen as tools that allow a sustainable urban planning under UM.

\section{URBAN METABOLISM}

Although studies that examine mass and energy in urban environments refer to the usage of diverse terminologies, often they are called urban metabolic analysis [1]. Cities have been compared to biological organisms, since they require energy and resources to transform them and convert them into work and waste. However, it is preferable to compare them not as the metabolism of a single agency but as an ecosystem or as the sum of ecosystems [14]. From this perspective, a city could be considered as a "new" ecosystem that has seen little development [6]. In this space, humans exchange materials and energy with the outside [15], in order to feed, work, live, transport and communicate [16].

\subsection{Methods used to evaluate urban metabolism}

Studies on UM use two general types of methodologies; on the one hand, are those that are based on an inventory of inputs and outputs (materials and energy), and on the other, those that use biophysical indicators that allow to represent the resources and energy efficiency in terms of emergy and exergy [4, 14, 17].

A specific categorization used to evaluate the urban energy profile, is based on Chen and Chen [18]:

- Urban energy flows: which allow to monitor the direct energy consumption and it is possible to relate the energy imported and exported depending on the type of fuel used $[18,19]$. 


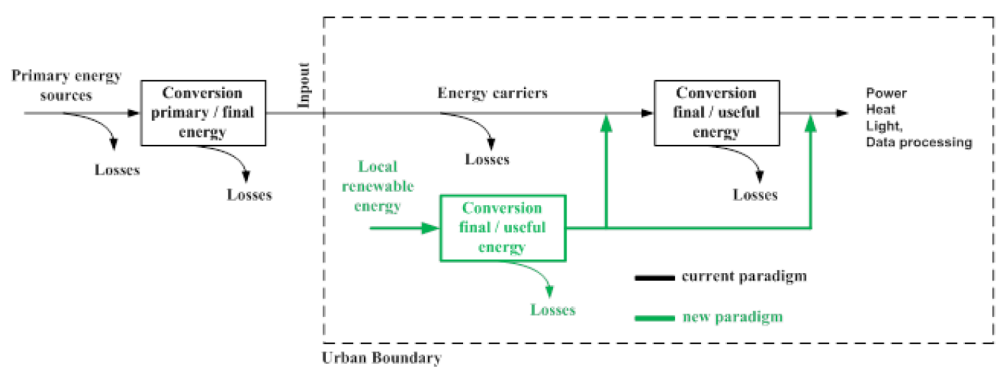

Figure1: The use of renewable energy in order to promote circular urban metabolism.

- Analysis of inputs and outputs: that allows to assess the direct and indirect energy provided by two different productive sectors. Relationships between them are measured in terms of energy, as a function of what one sector contributes to the other [20, 21].

- Analysis of ecological networks: allows for evaluation of the direct and indirect energy between various productive sectors. This approach considers that each sector has linkages with other sectors $[18,20]$.

Unlike UM that evaluates the inputs and outputs of materials, energy has a behaviour that differs, since it is not reversible. Energy allows the processing of materials and in spite of the fact that it can be stored, it generally dissipates [21]. The energy that enters the socio-economic system is known as direct energy [19]. This energy is the sum of the energy of domestic extraction and imported energy. In the first case, this energy is attributed to biomass energy within the study area. Imported energy, corresponds to the external energy, which would include the energy carriers and the energy contained in the materials. A specific productive sector, in addition to direct energy requires indirect energy. Indirect energy is that which comes from another sector, for example, the energy that comes from products or services [18].

All the energy that enters a sector is known as energy embedded and is the sum of the direct and indirect energies [18, 22, 23]. The use of the direct energy allows only a partial analysis of the totality of energy required by a city. In fact, the direct energy accounts only to $40 \%$ of the total energy embedded [23]. According to Chen and Chen [18], in certain sectors indirect energy can be between 26 to 30 times more than the direct energy. For the purpose of this work, direct energy of carriers that requires a city is analysed, since it is sought to identify the types of renewable energy that can be used in cities.

With the knowledge that energy comes from energy carriers, it can be established that energy substitutes can be provided by renewable energy, and thereby being the first step to the proposal of changes. Likewise, reduction of energy flows from sources causing environmental impacts, emissions or waste, will involve the reduction of adverse effects. Figure 1 represents the use of renewable energy to promote circular UM.

\section{RENEWABLE ENERGIES WITHIN CITIES}

The energy sector is strategic; on the one hand, it allows to maintain a certain lifestyle and, on the other, it is a basic requirement for the economic development of a society [24]. Industrial revolution allowed for the advancement of the sciences and a vertiginous urban growth related to the intensive use of energy supported by the exploitation of fossil resources [14]. For more than 200 years the urban energy model has been based on the use of fossil 
fuels, first with coal which allowed for the industrial development followed by oil which has facilitated urban growth [15]; however, the "fossil fuel era" would be near its end within the next 100 to 200 years [16].

Energy self-sufficiency through renewable sources is an alternative to promote a closed energy cycle in urban areas [12], to the extent that it should replace technologies that require fossil resources. An individual evaluation must be done for each city, due to its geographical conditions, the availability of resources, or the energy use, which can all be limiting factors for the use of one technology versus another [9].

Unlike the fossil-fuel-based energy, renewable energy sources (RE) are considered sustainable, because they can contribute to energy needs without reducing the availability of energy sources in the future. In addition, REs can be used in distributed applications, promote local labour and constitute an indigenous resource, which would have a direct impact on the long-awaited energy sovereignty of any country or region.

In cities that have been built without considering the endogenous energy option, the buildings do not consider the incorporation of passive or active energy systems. Several studies have been conducted to show that it is possible for a city to become fully or partially energy self-sufficient. Páez [8], proposes that in conjunction with the renewable resources, bioclimatic architecture, energy efficiency and the implementation of programs that are directed to a circular pattern of UM must be promoted.

\subsection{Case study}

Literature that indicates proposals from several researchers to promote the use of the REs in the cities was analysed. So far, there is no single method for assessing the potential energy within a city. The applicable technologies depend on the existing resources as well as the requirements for their use. It is not clear which is the best option from a technological, social, environmental or economic point of view. The choice will also depend on the available resources, the intended benefits or decrease of externalities [13, 25].

The technologies chosen are those that can be used in the cities, and whose technological maturity enables them to supply a percentage of the demand. The Institute for Energy Saving and Diversification of Spain (IDAE in Spanish) [26], classifies 11 sectors and 22 renewable energy systems. Based on a literature review, the authors established 11 renewable energy systems that can be applied in cities. Table 1 shows some examples of these systems, and the percentage of energy demand that could be achieved with their implementation.

Systems were chosen whose resources were available within the city (biomass, solar, wind or geothermal energy) or come from it (waste or wastewater). Energy or materials that comes from outside is not considered because what is sought out is for the use of energy in a way that promotes circular urban energy metabolism. In the case of hydropower and the energies of the sea, even when there are experiences of its application in urban areas, their use would be limited in those cities that have the required conditions.

The research focuses not just on one sole technology, as it is intended for several renewable energies to be used in order to improve the performance or satisfy energy demand [27, 28].

\subsection{Planning in cities}

For cities in the twentieth century to be suitable for the health conditions of the people, infrastructure was created or public policies were proposed based on scientific knowledge. The 
Table 1: Examples of research on the use of renewable energy in cities.

\begin{tabular}{|c|c|c|c|c|c|}
\hline Sector & System & Reference & $\%$ Demand & Use & City \\
\hline \multirow[t]{2}{*}{ Biofuels } & Bioethanol & [29] & 12,6 & Thermal & Chinese Cities \\
\hline & Biodiesel & --- & --- & --- & --- \\
\hline \multirow[t]{3}{*}{ Biomass } & Gasification & --- & --- & --- & --- \\
\hline & Direct combustion & {$[30]$} & 4,36 & Electric & Mar del Plata \\
\hline & Co - combustion & --- & & & --- \\
\hline Biogas & Biogas & {$[31]$} & 120 & Electric & US cities \\
\hline \multirow[t]{3}{*}{ Waste } & $\begin{array}{l}\text { MSW* landfill } \\
\text { biogas }\end{array}$ & {$[32]$} & $6-40$ & Electric & $\begin{array}{l}\text { Mexicali, } \\
\text { Tijuana }\end{array}$ \\
\hline & $\begin{array}{l}\text { Incineration and } \\
\text { co-incineration }\end{array}$ & {$[33]$} & 12,44 & Electric & Brazil cities \\
\hline & MSW* gasification & --- & --- & --- & --- \\
\hline \multirow[t]{2}{*}{ Ocean energy } & Wave & --- & --- & Electric & --- \\
\hline & Currents & {$[34]$} & --- & & San Luis \\
\hline \multirow[t]{2}{*}{ Wind energy } & Onshore & {$[5]$} & 43 & Electric & Wageningen \\
\hline & Offshore & --- & --- & --- & --- \\
\hline \multirow[t]{2}{*}{ Geothermal } & $\begin{array}{l}\text { Electricity genera- } \\
\text { tion }\end{array}$ & --- & --- & --- & --- \\
\hline & Air conditioning & {$[35]$} & 100 & Thermal & Westminster \\
\hline Hydroelectric & Small hydro & {$[36]$} & --- & Electric & $\begin{array}{l}\text { Switzerland } \\
\text { village }\end{array}$ \\
\hline $\begin{array}{l}\text { Solar } \\
\text { photovoltaic }\end{array}$ & Photovoltaic & [11] & --- & Electric & Kerkrade \\
\hline Solar thermal & Solar thermal & {$[37]$} & 46,6 & Thermal & Mexico city \\
\hline \multirow{3}{*}{$\begin{array}{l}\text { Solar } \\
\text { thermoelectric }\end{array}$} & Central receiver & --- & --- & --- & --- \\
\hline & $\begin{array}{l}\text { Linear Fresnel } \\
\text { reflector }\end{array}$ & --- & --- & --- & --- \\
\hline & $\begin{array}{l}\text { Parabolic Dish } \\
\text { Stirling }\end{array}$ & --- & --- & --- & --- \\
\hline
\end{tabular}

*MSW, Municipal Solid Waste

goal, for example, was to provide the largest population with basic services or reduce diseases. The new paradigm for the twentyfirst century is changing because cities will have to cope with environmental changes and shortage of resources. Therefore, more than new infrastructures, the requirement will be for policies that promote the development of cities conditioning them to reduce their intake and to aim for a decline in waste generation [6].

It is proposed that cities are designed as a system with a circular metabolism [11]. To contribute to the development of renewable energies at the regional level, it is necessary to establish long-term strategies that point to a sustainable energy system based on available resources [24]. In this sense, Haberl [19] explains that the knowledge of the analyses that is derived from studies of material and energy flows will increase the efficiency of the resources used. 
Haberl [19] suggests that urban planning must be conditioned by the requirements of sustainability. In this sense, proper management of resources that consider several topics is required, relating to the provision of water, energy and materials, public infrastructure, commerce and industry. To encourage the use of renewable energy, it will be required to accompany it with implementation of legal framework, tools, education and successful examples. In new sites, from the start planners can establish conditions to promote buildings that embrace the principles of bioclimatic or renewable technologies.

\section{CONCLUSIONS}

$\mathrm{UM}$ is a tool that allows the identification of the material and energy flows within the city. Its purpose is to properly manage the resources that are required by cities without compromising the quality of life of the people or the environment from where the resources are obtained. One of the requirements of the current society is the use of renewable energies; however, in the planning of cities these are not being considered as mechanisms to reduce the importation of energy.

UM aims to know, among others, energy flows. To establish which renewable technologies can be applied in a city, determining the flow of energy carriers is suggested as a first step to propose changes in the management of energy locally. Knowing the UM energy of a city, energy resources and renewable technologies, it will allow for the proposal of policies that encourage the implementation of one or multiple technologies.

This paper describes that renewable energies can be used to promote circular UM. Several investigations show that part of the energy demand of a city can be covered by REs. However, the special conditions of a city, its location and energy requirements are limitations to the extensive use of a single technology.

Through a literature review, 11 renewable technologies with different degrees of maturity have been identified, which can be applied in cities. Costs associated with the operation and maintenance and lack of empathy with the environmental events, prevent social acceptance and, therefore, its massive use. However, the need for a more sustainable energy system and the future role of cities will require to design new policies and planning processes to promote the use of renewable energies in urban areas, taking advantage of local resources.

The use of RE's within cities means a change of the current energy model. The proposed paradigm is reflected in the decrease in the import of energy resources outside the city. The utilization of energy resources will decrease the dependence on non-renewable resources pollutants, reduction of externalities related to construction and operation of large transport and power generation infrastructures. In addition, it would have an impact on the losses associated with energy transport.

The proposal, however, involves several challenges. This will have an impact on the way cities are planned and will also require a change in the patterns of energy and material consumption. It is essential to be a more committed society with regard to environmental problems and, therefore, the sufficiency of energy as a guarantee for achieving sustainable development.

As a complement to this study, the authors encourage to deepen the analysis, by first investigating the energy situation in a city. Once renewable technologies that can meet current demands are identified, it is possible to create local energy scenarios and by using sustainability indicators proposed options can be formulated. In addition to obtaining knowledge of the energy situation in the cities, the interests of those involved prior to implementing a local policy should also be considered. 


\section{REFERENCES}

[1] Ngo, N.S. \& Pataki, D.E., Energy and mass balance of Los Angeles County. Urban Ecosystems, 11(2), pp. 121-139, 2008. http://dx.doi.org/10.1007/s11252-008-0051-1

[2] Barles, S., Urban metabolism of paris and its region. Journal of Industrial Ecology, 13(6), pp. 893-913, 2009. http://dx.doi.org/10.1111/j.1530-9290.2009.00169.x

[3] Keirstead, J., Jennings, M. \& Sivakumar, A., A review of urban energy system models: approaches, challenges and opportunities. Renewable and Sustainable Energy Reviews, 16(6), pp. 3847-3866, 2012. http://dx.doi.org/10.1016/j.rser.2012.02.047

[4] Chen, S. \& Chen, B., Network environ perspective for urban metabolism and carbon emissions: a case study of Vienna, Austria. Environmental Science \& Technology, 46(8), pp. 4498-4506, 2012. http://dx.doi.org/10.1021/es204662k

[5] Agudelo-Vera, C.M., Leduc, W.R.W.A., Mels, A.R. \& Rijnaarts, H.H.M., Harvesting urban resources towards more resilient cities. Resources, Conservation and Recycling, 64, pp. 3-12, 2012. http://dx.doi.org/10.1016/j.resconrec.2012.01.014

[6] Pincetl, S., Nature, urban development and sustainability - what new elements are needed for a more comprehensive understanding? Cities, 29, pp. 32-33, 2012. http://dx.doi.org/10.1016/j.cities.2012.06.009

[7] Ren, H., Zhou, W., Nakagami, K., Gao, W. \& Wu, Q., Feasibility assessment of introducing distributed energy resources in urban areas of China. Applied Thermal Engineering, 30(16), pp. 2584-2593, 2010. http://dx.doi.org/10.1016/j.applthermaleng.2010.07.009

[8] Páez, A., Energy-urban transition: the Mexican case. Energy Policy, 38(11), pp. 72267234, 2010. http://dx.doi.org/10.1016/j.enpol.2010.07.053

[9] Grewal, P.S. \& Grewal, P.S., Can cities become self-reliant in energy? a technological scenario analysis for Cleveland. Cities, 31, pp. 404-411, 2013. http://dx.doi.org/10.1016/j.cities.2012.05.015

[10] Agudelo-Vera, C.M., Mels, A.R., Keesman, K.J. \& Rijnaarts, H.H.M., Resource management as a key factor for sustainable urban planning. Journal of Environmental Management, 92(10), pp. 2295-2303, 2011.

http://dx.doi.org/10.1016/j.jenvman.2011.05.016

[11] Leduc, W.R.W.A. \& Van Kann, F.M.G., Spatial planning based on urban energy harvesting toward productive urban regions. Journal of Cleaner Production, 39, pp. 180-190, 2013. http://dx.doi.org/10.1016/j.jclepro.2012.09.014

[12] Kennedy, C., Cuddihy, J. \& Engel-Yan, J., The changing metabolism of cities. Journal of Industrial Ecology, 11(2), pp. 43-59, 2007. http://dx.doi.org/10.1162/jie.2007.1107

[13] Vandevyvere, H. \& Stremke, S., Urban planning for a renewable energy future: methodological challenges and opportunities from a design perspective. Sustainability, 4(6), pp. 1309-1328, 2012.

http://dx.doi.org/10.3390/su4061309 
[14] Pincetl, S., Bunje, P. \& Holmes, T., An expanded urban metabolism method: toward a systems approach for assessing urban energy processes and causes. Landscape and Urban Planning, 107(3), pp. 193-202, 2012. http://dx.doi.org/10.1016/j.landurbplan.2012.06.006

[15] Huang, S.-L. \& Chen, C.-W., Theory of urban energetics and mechanisms of urban development. Ecological Modelling, 189(1-2), pp. 49-71, 2005. http://dx.doi.org/10.1016/j.ecolmodel.2005.03.004

[16] Brunner, P.H., Reshaping urban metabolism. Journal of Industrial Ecology, 11(2), pp. 11-13, 2007. http://dx.doi.org/10.1162/jie.2007.1293

[17] Kennedy, C., Pincetl, S. \& Bunje, P., The study of urban metabolism and its applications to urban planning and design. Environmental Pollution, 159(8-9), pp. 1965-1973, 2011. http://dx.doi.org/10.1016/j.envpol.2010.10.022

[18] Chen, S. \& Chen, B., Urban energy consumption: different insights from energy flow analysis, input-output analysis and ecological network analysis. Applied Energy, 138, pp. 99-107, 2015. http://dx.doi.org/10.1016/j.apenergy.2014.10.055

[19] Haberl, H., Energetic metabolism of societies part I: accounting concepts. Journal of Industrial Ecology, 5(1), pp. 11-33, 2001. http://dx.doi.org/10.1162/108819801753358481

[20] Zhang, Y., Urban metabolism: a review of research methodologies. Environmental Pollution, 178, pp. 463-473, 2013. http://dx.doi.org/10.1016/j.envpol.2013.03.052

[21] Proops, J.L.R., Input-output analysis and energy intensities: a comparison of some methodologies. Applied Mathematical Modelling, 1(14), pp. 181-186, 1977. http://dx.doi.org/10.1016/0307-904X(77)90003-8

[22] Zhang, L., Hu, Q. \& Zhang, F., Input-output modeling for urban energy consumption in Beijing: dynamics and comparison. PloS One, 9(3), pp. 1-11, 2014. http://dx.doi.org/10.1371/journal.pone.0089850

[23] Zhang, Y., Zheng, H. \& Fath, B.D., Analysis of the energy metabolism of urban socioeconomic sectors and the associated carbon footprints: model development and a case study for Beijing. Energy Policy, 73, pp. 540-551, 2014. http://dx.doi.org/10.1016/j.enpol.2014.04.029

[24] Terrados, J., Almonacid, G. \& Pérez-Higueras, P., Proposal for a combined methodology for renewable energy planning. Application to a Spanish region. Renewable and Sustainable Energy Reviews, 13(8), pp. 2022-2030, 2009. http://dx.doi.org/10.1016/j.rser.2009.01.025

[25] Arodudu, O., Ibrahim, E., Voinov, A. \& van Duren, I., Exploring bioenergy potentials of built-up areas based on NEG-EROEI indicators. Ecological Indicators, 47, pp. 67-79, 2014. http://dx.doi.org/10.1016/j.ecolind.2014.04.042

[26] Plan de Energías Renovables 2011 2020; IDAE, Online, available at http://www.idae. es/index.php/id.670/relmenu.303/mod.pags/mem.detalle

[27] Palmas, C., Jensen, H., Haaren, C.V. \& Schöner, R., Optimizing micro renewable generation for smart cities by combining solar and geothermal energy potentials a case study of the Hannover region. 3rd International Conference on Smart Grids and Green IT Systems, SciTePress: Barcelona, pp. 283-288, 2012. 
[28] Shi, Y., Ge, Y., Chang, J., Shao, H. \& Tang, Y., Garden waste biomass for renewable and sustainable energy production in China: potential, challenges and development. Renewable and Sustainable Energy Reviews, 22, pp. 432-437, 2013. http://dx.doi.org/10.1016/j.rser.2013.02.003

[29] Yeo, I.-A. \& Yee, J.-J., A proposal for a site location planning model of environmentally friendly urban energy supply plants using an environment and energy geographical information system (E-GIS) database (DB) and an artificial neural network (ANN). Applied Energy, 119, pp. 99-117, 2014. http://dx.doi.org/10.1016/j.apenergy.2013.12.060

[30] Roberts, J.J., Cassula, A.M., Osvaldo Prado, P., Dias, R.A. \& Balestieri, J.A.P., Assessment of dry residual biomass potential for use as alternative energy source in the party of general Pueyrredón, Argentina. Renewable and Sustainable Energy Reviews, 41, pp. 568-583, 2015. http://dx.doi.org/10.1016/j.rser.2014.08.066

[31] Shen, Y., Linville, J.L., Urgun-Demirtas, M., Mintz, M.M. \& Snyder, S.W., An overview of biogas production and utilization at full-scale wastewater treatment plants (WWTPs) in the United States: challenges and opportunities towards energy-neutral WWTPs. Renewable and Sustainable Energy Reviews, 50, pp. 346-362, 2015. http://dx.doi.org/10.1016/j.rser.2015.04.129

[32] Aguilar-Virgen, Q., Taboada-González, P. \& Ojeda-Benítez, S., Analysis of the feasibility of the recovery of landfill gas: a case study of Mexico. Journal of Cleaner Production, 79, pp. 53-60, 2014.

http://dx.doi.org/10.1016/j.jclepro.2014.05.025

[33] de Souza, S.N., Horttanainen, M., Antonelli, J., Klaus, O., Lindino, C. \& Nogueira, C.E., Technical potential of electricity production from municipal solid waste disposed in the biggest cities in Brazil: landfill gas, biogas and thermal treatment. Waste Management \& Research: The Journal of the International Solid Wastes and Public Cleansing Association, ISWA, 32(10), pp. 1015-1023, 2014. http://dx.doi.org/10.1177/0734242X14552553

[34] Leite Neto, P.B., Saavedra, O.R. \& Souza Ribeiro, L.A., Optimization of electricity generation of a tidal power plant with reservoir constraints. Renewable Energy, 81, pp. 11-20, 2015. http://dx.doi.org/10.1016/j.renene.2015.03.011

[35] Zhang, Y., Choudhary, R. \& Soga, K., Influence of GSHP system design parameters on the geothermal application capacity and electricity consumption at city-scale for Westminster, London. Energy and Buildings, 106, pp. 3-12, 2015. http://dx.doi.org/10.1016/j.enbuild.2015.07.065

[36] Orehounig, K., Evins, R., Dorer, V. \& Carmeliet, J., Assessment of renewable energy integration for a village using the energy hub concept. Solar World Congress, Elsevier: Cancún, pp. 940-949, 2013.

[37] Rosas-Flores, J.A., Rosas-Flores, D. \& Fernández Zayas, J.L., Potential energy saving in urban and rural households of Mexico by use of solar water heaters, using geographical information system. Renewable and Sustainable Energy Reviews, 53, pp. 243-252, 2016.

http://dx.doi.org/10.1016/j.rser.2015.07.202 